\title{
Genetic and nongenetic variation in plasma and milk $\beta$-hydroxybutyrate and milk acetone concentrations of early-lactation dairy cows
}

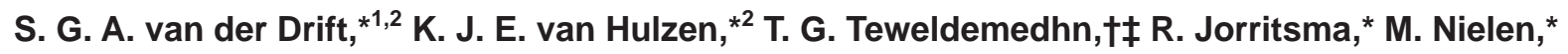 \\ and H. C. M. Heuven†§ \\ *Department of Farm Animal Health, Utrecht University, PO Box 80151, 3508 TD Utrecht, the Netherlands \\ †Animal Breeding and Genomics Centre, Wageningen University, PO Box 338, 6700 AH Wageningen, the Netherlands \\ $\ddagger$ School of Animal and Range Sciences, College of Agriculture and Environmental Sciences, Haramaya University, PO Box 282, \\ Haramaya, Ethiopia \\ §Clinical Sciences of Companion Animals, Utrecht University, PO Box 80163, 3508 TD Utrecht, the Netherlands
}

\begin{abstract}
This study assessed genetic variation, heritability estimates, and genetic correlations for concentrations of plasma $\beta$-hydroxybutyrate (BHBA), milk BHBA, and milk acetone in early lactation to investigate differences between cows in susceptibility to hyperketonemia and possibilities to use test-day milk ketone bodies for genetic improvement. Blood and test-day milk samples were collected on randomly selected dairy farms in the Netherlands from cows of various parities between 5 and $60 \mathrm{~d}$ in milk. Plasma samples were analyzed for BHBA (reference test for hyperketonemia) and testday milk samples were analyzed for BHBA and acetone using Fourier-transform infrared spectroscopy. The final data set consisted of plasma BHBA concentrations of 1,615 cows from 122 herds. Milk BHBA and milk acetone concentrations were determined for 1,565 cows. Genetic variation, heritability, and proportion of phenotypic variation attributable to the herd were estimated using an animal model with fixed effects for parity and season, a covariate for days in milk, and random effects for herd, animal, and error. Genetic correlations for plasma BHBA, milk BHBA, and milk acetone were estimated using bivariate analyses. The heritability estimate for plasma BHBA concentrations in early lactation was 0.17 , whereas heritability estimates for milk BHBA and milk acetone were 0.16 and 0.10 , respectively. This indicates that selective breeding may contribute to a lower incidence of hyperketonemia in early lactation. For the 3 traits, the proportion of variance attributable to herd was larger than the additive genetic variance, underlining the importance of on-farm feeding and management in the etiology of hyperketonemia in fresh cows. Prevention strategies for
\end{abstract}

Received April 19, 2012

Accepted June 29, 2012.

${ }^{1}$ Corresponding author: sgavanderdrift@gmail.com

${ }^{2}$ These authors contributed equally to this work. hyperketonemia can, therefore, include both feeding and management strategies at dairy farms (short-term) and genetic improvement through breeding programs (long-term). Genetic correlations between concentrations of plasma BHBA and milk BHBA (0.52) or milk acetone (0.52) were moderate. As milk ketone bodies can be routinely analyzed at test days, this may provide a practical alternative for breeding programs aimed at reducing hyperketonemia in early lactation.

Key words: genetic variation, $\beta$-hydroxybutyrate, acetone, dairy cow

\section{INTRODUCTION}

Hyperketonemia or subclinical ketosis is an important metabolic disorder in early-lactation dairy cows, as it is associated with reduced milk production (Duffield et al., 2009), reduced reproductive performance (Walsh et al., 2007), and increased risks for clinical ketosis (Seifi et al., 2011) and displaced abomasum (LeBlanc et al., 2005). The disease is characterized by an increased blood concentration of ketone bodies and is caused by inadequate hepatic metabolism of NEFA (excessively) mobilized from adipose tissue during negative energy balance (NEB). Genetic selection of cows for milk production has resulted in larger NEB and larger mobilization of body reserves in early lactation (Veerkamp et al., 2003). This would suggest an increased risk for hyperketonemia in high-genetic merit cows, although variability in the adaptation to NEB exists between individual animals. For example, Kessel et al. (2008) showed that energy balance and milk yield were similar in high-yielding cows with high versus low plasma BHBA concentrations after calving. In addition, Oikonomou et al. (2008b) observed no genetic correlation between energy balance traits and serum BHBA concentrations in early-lactation primiparous cows. The challenge is to use the existing genetic variation in metabolic adaptation to NEB to select for high-producing cows with a low susceptibility to hyperketonemia in early lactation. 
Previous studies on the genetic background of ketosis susceptibility mostly focused on genetic variation in the occurrence of clinical ketosis based on clinical records in health monitoring or farm management programs. Those studies reported heritability estimates for clinical ketosis ranging from 0.02 to 0.39 (Gröhn et al., 1984; Mäntysaari et al., 1991; Uribe et al., 1995; Van Dorp et al., 1998; Heringstad et al., 2005). Heritability estimates for clinical ketosis may, however, be influenced by the subjective nature of its diagnosis and the low frequency of clinical ketosis compared with hyperketonemia in cows. Blood concentrations of the ketone body BHBA are generally used as reference for hyperketonemia and likely represent the biological variation in ketosis susceptibility in cows more precisely. Oikonomou et al. (2008b) estimated heritabilities for serum BHBA concentrations of 0.40 to 0.08 for the first 7 wk of lactation in primiparous cows. The prevalence of hyperketonemia increases with parity (Duffield et al., 1997; van der Drift et al., 2012b). Genetic parameters for plasma BHBA concentrations have, however, not been estimated for multiparous cows in early lactation.

Plasma BHBA concentrations of cows are not routinely available in practice. Measurements of milk concentrations of BHBA and acetone could instead be implemented as an indicator for hyperketonemia in breeding programs for dairy cows, as these can be routinely analyzed by Fourier-transform infrared (FTIR) spectroscopy analysis in milk samples at test days (de Roos et al., 2007). Low heritability estimates for milk acetone concentrations in early lactation have been reported (Emanuelson and Andersson, 1986; Wood et al., 2004), but no estimates of milk BHBA concentrations were found. The objectives of this study were to estimate genetic and nongenetic variation and heritabilities for concentrations of plasma BHBA, milk BHBA, and milk acetone in early lactation and to determine phenotypic and genetic correlations between these traits in Dutch dairy cows.

\section{MATERIALS AND METHODS}

\section{Farm and Animal Selection}

The experiment was evaluated and approved by the Ethical Committee on Animal Experiments from Utrecht University (Utrecht, the Netherlands). Data and samples originated from the study of van der Drift et al. (2012b) on the detection of hyperketonemia in cows using test-day information. In short, 1,772 cows of various parities from 123 randomly selected dairy farms in the Netherlands were enrolled in the study from November 2009 to November 2010. Farms were visited once at a regular test day and all cows between 5 and 60 DIM (high-risk period for hyperketonemia) participating in the milk recording were sampled. Farm visits were equally distributed over the year.

\section{Sampling Protocol and Sample Analysis}

Sampling protocol and sample analysis were described elsewhere (van der Drift et al., 2012b). In short, test-day milk sampling and analysis were all performed according to the standard milk-recording procedures. Milk samples were combined evening and morning samples. Blood samples were drawn from a coccygeal blood vessel from all eligible cows between 1100 and $1400 \mathrm{~h}$ for plasma analysis of BHBA (reference test for hyperketonemia) after morning test-day milk sampling. Plasma samples were analyzed for BHBA using a Randox test kit (Ranbut kit; Randox laboratories Ltd., Crumlin, UK). Test-day milk samples were analyzed according to regular test-day procedures at the laboratory of Qlip NV (Zutphen, the Netherlands) by FTIR spectroscopy analysis using a MilkoScan FT600 apparatus (Foss Analytical A/S, Hillerød, Denmark) with operational calibrations for BHBA and acetone (de Roos et al., 2007).

\section{Data Editing}

Test-day records, pedigree information, and expected values $(\mathbf{E V})$ for milk production at first lactation based on breeding values of sire and dam (milk production potential) were provided by the Cattle Improvement Co-operative (CRV) organization (Arnhem, the Netherlands). Cow records were excluded from further analysis cases of incorrect stage of lactation $(<5$ or $>60$ DIM) at sampling $(\mathrm{n}=18)$, unknown calving date ( $\mathrm{n}$ $=4)$, missing test-day results $(\mathrm{n}=7)$, and missing $\mathrm{EV}$ for milk production $(\mathrm{n}=128)$. Selected cows originated from 571 sires and 1,551 dams and for each cow, pedigree information was available up to a maximum of 21 generations. Finally, 1,615 cows from 122 farms were included in the data analysis. Plasma BHBA concentration was available from all cows; milk BHBA and milk acetone concentrations were determined for 1,565 cows.

\section{Statistical Analysis}

Variance components for genetic and herd effects were estimated using an animal model in ASReml software (Gilmour et al., 2009):

$$
Y_{i j k l m}=\mu+P_{i}+D I M_{j}+S_{k}+H_{l}+A n_{m}+e_{i j k l m},
$$


where $Y_{i j k l m}$ is the log-transformed value for plasma BHBA, milk BHBA, or milk acetone; $\mu$ is the general mean; $P_{i}$ is the fixed effect of the $i$ th parity $(i=1,2$, 3 , or $\geq 4) ; D I M_{j}$ is the covariate describing the effect of days in milk; $S_{k}$ is the fixed effect of the $k$ th season of sampling: summer (June-August), autumn (September-November), winter (December-February), and spring (March-May); $H_{l}$ is the random effect of herd $l ; A n_{m}$ is the random additive genetic effect of animal $m$; and $e_{i j k l m}$ is the random residual component. Milk BHBA concentrations were raised by $0.01 \mathrm{mmol} / \mathrm{L}$ to transform negative values (FTIR analysis may lead to negative values) and allow $\log$ transformation of the data. The following distributional assumptions were made with respect to the random effects:

$$
\begin{aligned}
& \mathbf{H} \sim N\left(0, \mathbf{I} \sigma_{\text {herd }}^{2}\right), \\
& \mathbf{A n} \sim N\left(0, \mathbf{A} \sigma_{a}^{2}\right),
\end{aligned}
$$

and

$$
\mathbf{e} \sim N\left(0, \mathbf{I} \sigma_{e}^{2}\right)
$$

where $\mathbf{H}$ is the vector included in the herd effect, $\mathbf{A n}$ is the vector included in the additive genetic effect, $\mathbf{e}$ is the vector included in the residual effect, $\mathbf{I}$ is an identity matrix of appropriate size, $\sigma_{\text {herd }}^{2}$ represents the herd variance, $\mathbf{A}$ is the relationship matrix, $\sigma_{a}^{2}$ represents the additive genetic variance, and $\sigma_{e}^{2}$ represents the residual variance. Variance components were used to estimate the heritability $\left(h^{2}\right)$, which was defined as follows:

$$
h^{2}=\frac{\sigma_{a}^{2}}{\sigma_{a}^{2}+\sigma_{h e r d}^{2}+\sigma_{e}^{2}},
$$

where $\sigma_{a}^{2}+\sigma_{\text {herd }}^{2}+\sigma_{e}^{2}$ reflects the phenotypic variance $\left(\sigma_{p}^{2}\right)$. The proportion of variance attributable to herd $\left(h_{\text {herd }}\right)$ reflects the relative importance of herd effects, such as feeding and management, and was estimated as

$$
h_{\text {herd }}=\frac{\sigma_{\text {herd }}^{2}}{\sigma_{a}^{2}+\sigma_{\text {herd }}^{e}+\sigma_{e}^{2}} .
$$

Additionally, the ratio between the $\sigma_{a}^{2}$ and the $\sigma_{\text {herd }}^{2}$ $\left(\sigma_{a}^{2} / \sigma_{\text {herd }}^{2}\right)$ was calculated for each trait to compare the relative importance of genetic and herd effects.

Phenotypic $\left(r_{p}\right)$ and genetic correlations $\left(r_{g}\right)$ for plasma BHBA concentration with milk BHBA and milk acetone concentrations were estimated using bivariate analyses and model [1] as

$$
r_{p}=\frac{\sigma_{p 1, p 2}^{2}}{\sqrt{\left(\sigma_{p 1}^{2} \times \sigma_{p 2}^{2}\right)}},
$$

and

$$
r_{g}=\frac{\sigma_{a 1, a 2}^{2}}{\sqrt{\left(\sigma_{a 1}^{2} \times \sigma_{a 2}^{2}\right)}},
$$

where $\sigma_{p 1, p 2}^{2}$ is the phenotypic covariance between trait 1 and trait $2, \sigma_{p 1}^{2}$ and $\sigma_{p 2}^{2}$ are the phenotypic variances of trait 1 and trait $2, \sigma_{a 1, a 2}^{2}$ is the additive genetic covariance between trait 1 and trait 2 , and $\sigma_{a 1}^{2}$ and $\sigma_{a 2}^{2}$ are the additive genetic variances of trait 1 and trait 2 .

To assess the association of hyperketonemia susceptibility with milk production potential, variance components for genetic and herd effects were reestimated using model [1] with inclusion of EV for milk production at first lactation (milk production potential) as a covariate in the model.

To test the hypotheses that the heritability and the proportion of variance attributable the herd are significantly different from zero, likelihood-ratio tests were performed as twice the difference in log-likelihoods between the full models and the reduced models either without the random genetic effect or without the random herd effect. For a single variance component, the theoretical asymptotic distribution of the likelihoodratio test is a mixture of $\chi^{2}$ variates, where the mixing probabilities are 0.5 , one with 0 degrees of freedom and the other with 1 degree of freedom (Gilmour et al., 2009). Significance of the phenotypic and genetic correlations was assessed by comparing the likelihood of the previously described bivariate models containing the phenotypic or genetic covariance component, with the reduced models in which the phenotypic or genetic covariance was fixed at 0 , again using likelihood-ratio tests.

\section{RESULTS}

\section{Phenotypic Variation}

Mean, standard deviation, and minimum and maximum values for concentrations of plasma BHBA, milk BHBA, and milk acetone are shown in Table 1. Results show considerable variation for all 3 traits. 
Table 1. Mean, SD, and minimum and maximum values for concentrations of plasma BHBA (mmol/L), milk BHBA $(\mathrm{mmol} / \mathrm{L})$, and milk acetone $(\mathrm{mmol} / \mathrm{L})$ in dairy cows of various parities between 5 and 60 DIM

\begin{tabular}{lccccc}
\hline Trait & $\mathrm{n}$ & Mean & $\mathrm{SD}$ & Minimum & Maximum \\
\hline Plasma BHBA & 1,615 & 0.76 & 0.56 & 0.16 & 7.05 \\
Milk BHBA & 1,565 & 0.08 & 0.08 & $-0.01^{1}$ & 0.79 \\
Milk acetone & 1,565 & 0.10 & 0.12 & 0.01 & 1.37 \\
\hline
\end{tabular}

${ }^{1}$ Fourier-transform infrared spectroscopy analysis may lead to negative values.

\section{Heritability and Proportion of Variance Attributable to Herd}

Variance components and heritability estimates for concentrations of plasma BHBA, milk BHBA, and milk acetone are shown in Table 2. The heritability estimate for plasma BHBA concentrations (reference test for hyperketonemia) in early lactation was moderate (0.17); heritability estimates for milk BHBA and milk acetone were 0.16 and 0.10 , respectively. For all traits, heritability estimates decreased slightly after inclusion of expected milk production at first lactation (EV for milk production) as a covariate in the model due to a decrease in additive genetic variation.

Results for the proportion of variance attributable to herd are shown in Table 2. For plasma BHBA and milk $\mathrm{BHBA}$, the proportion of variance attributable to herd was larger compared with milk acetone. For all 3 traits, this proportion hardly changed after inclusion of milk production potential in the model. The ratio of additive genetic variance over herd variance shows that additive genetic variance was smaller than the proportion of variance attributable to herd for all traits.

\section{Phenotypic and Genetic Correlations}

Phenotypic and genetic correlations for concentrations of plasma BHBA, milk BHBA, and milk acetone are shown in Table 3. All correlations were positive. Plasma BHBA concentrations had a moderate phenotypic and genetic correlation with milk BHBA and milk acetone concentrations. Phenotypic and genetic correlations between BHBA and acetone concentrations in milk were high.

\section{DISCUSSION}

This study assessed genetic and nongenetic variation and heritability estimates for concentrations of plasma BHBA, milk BHBA, and milk acetone in early lactation to investigate differences between cows in susceptibility to hyperketonemia and possibilities to use test-day milk ketone bodies for genetic improvement. Data were collected from a field study (van der Drift et al., 2012b) comprising randomly selected dairy farms, and the data set was, therefore, considered as being representative of dairy practice in the Netherlands. As the prevalence of hyperketonemia varies across parity, stage of lactation and season in cows (Duffield et al., 1997; van der Drift et al., 201Xa, accepted for publication in JDS), these factors were corrected for in the models. The study design did not allow for a robust evaluation of the effect of season on investigated traits in cows because herds were only visited once in a particular season. The variable season was, however, included in the model because herds were randomly selected throughout the year and approximately 30 herds were visited per season. Herd was investigated as a random effect in all models because the number of sampled cows was limited for most herds and herds were randomly selected from the Dutch population (no preselection for levels of plasma or milk ketone bodies across herds was done).

Herds can be monitored for hyperketonemia by regular assessment of the percentage of (a sample of) fresh cows having plasma BHBA concentrations above a defined threshold value (Oetzel, 2004). Hyperketonemia is then practically considered as an all-or-none state in individual cows, but this does not reflect the biological variation in plasma BHBA concentrations or the severity of hyperketonemia in cows. We therefore used plasma BHBA concentrations rather than presence or absence of hyperketonemia in cows to investigate genetic variation in ketosis susceptibility. The estimated heritability for plasma BHBA concentrations in early lactation ( 5 to $60 \mathrm{DIM}$ ) of cows of all parities was 0.17 in this study. This suggests that genetic selection for lower BHBA concentrations in early lactation seems possible, which was also concluded by Oikonomou et al. (2008b), who obtained heritability estimates of serum BHBA concentrations in primiparous cows ranging from 0.40 in the first lactation week to 0.08 in wk 7 of lactation. Our heritability estimate for plasma BHBA is also within the range of heritabilities of 0.02 to 0.39 in several studies on clinical ketosis (Gröhn et al., 1984; Mäntysaari et al., 1991; Uribe et al., 1995; Van Dorp et al., 1998; Heringstad et al., 2005), although we focused on genetic variation in hyperketonemia and did not distinguish between cows with or without clinical signs of ketosis during data collection. Heritability estimates of plasma (0.17) and milk (0.16) concentrations of BHBA 
Table 2. Additive genetic variance $\left(\sigma_{a}^{2}\right)$, proportion of variance attributable to herd $\left(\sigma_{\text {herd }}^{2}\right)$, residual variance $\left(\sigma_{e}^{2}\right)$, heritability $\left(h^{2}\right)$, proportion of variance attributable to herd $\left(h_{\text {herd }}\right)$, and ratio of additive genetic variance over herd variance for concentrations of plasma BHBA (mmol/L), milk BHBA (mmol/L), and milk acetone $(\mathrm{mmol} / \mathrm{L})$ in dairy cows between 5 and 60 DIM (SE of estimates in parentheses) before and after correction for milk production potential ${ }^{1,2}$

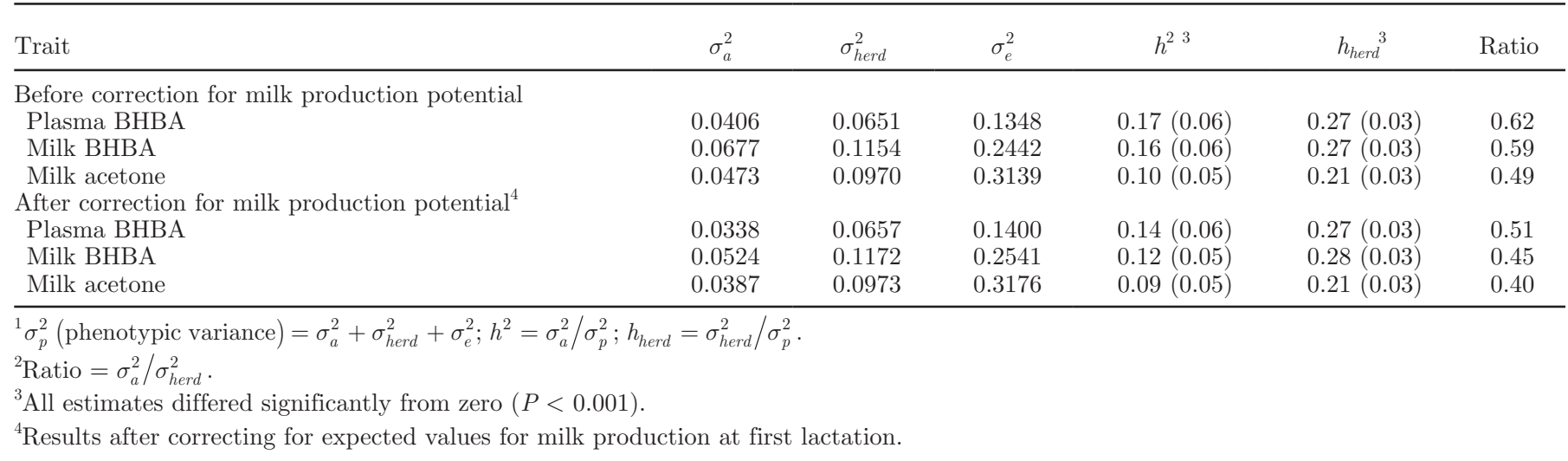

in early-lactation cows were similar in this study. Heritability of milk acetone concentration (0.10) was somewhat lower, because a larger part of the observed variation could not be assigned to fixed and random effects included in the model (larger residual variance). The heritability estimate was, however, still different from zero, and higher when compared with previous studies on genetic variation in milk acetone concentration (Emanuelson and Andersson, 1986; Wood et al., 2004).

High-producing cows are expected to be more prone to develop hyperketonemia, as it was shown that highgenetic merit cows experience more severe NEB in early lactation (Veerkamp et al., 2003; Coffey et al., 2004). Positive genetic correlations between milk production and clinical ketosis (Uribe et al., 1995) as well as plasma concentrations of the ketone body acetoacetate (Tveit et al., 1992) have been described. Genetic selection for lower ketosis susceptibility might, therefore, indirectly result in selection for lower milk production potential. In our opinion, the aim should be to select for cows with favorable metabolic adaptation to NEB, independent of milk production capacity. In the case of hyperketonemia, studying genetic correlations with milk production performance may not provide this information. The genetic correlation between plasma BHBA concentrations and test-day milk production data will be influenced by the negative effect of hyperketonemia on the milk production of cows (Duffield et al., 2009). In our study, the test-day milk production (mean $\pm \mathrm{SD}$ ) of cows was similar in cows with hyperketonemia $(35.8 \pm 7.7)$ and without hyperketonemia $(35.7 \pm 8.4 \mathrm{~kg})$, but cows with hyperketonemia (plasma BHBA concentration $\geq 1.20$ $\mathrm{mmol} / \mathrm{L}$ ) produced less milk than expected based on their breeding value (van der Drift et al., 2012b). Actual milk production, either at the test day or during the full lactation, may thus not be best suited to test for genetic differences in ketosis susceptibility of cows. The expected breeding value for milk production at first lactation can be considered as a proxy for genetic potential for milk production level of cows, which is not influenced by disease occurrence during lactation (hyperketonemia or clinical ketosis) or farm management. We included this expected milk production level for all cows (irrespective of actual parity in the study) in the models to reestimate genetic and nongenetic parameters and heritability estimates for concentrations of plasma BHBA, milk BHBA, and milk acetone in early lactation. The heritability estimate of plasma BHBA concentration in early lactation decreased to a minor extent after correction for expected milk production level, indicating that hyperketonemia susceptibility is

Table 3. Phenotypic (above diagonal) and genetic correlations (below diagonal) among concentrations of plasma BHBA (mmol/L), milk BHBA (mmol/L), and milk acetone $(\mathrm{mmol} / \mathrm{L})$ as estimated from samples of 1,565 dairy cows between 5 and 60 DIM (SE of estimates in parentheses)

\begin{tabular}{lccc}
\hline Trait & Plasma BHBA & Milk BHBA & Milk acetone \\
\hline Plasma BHBA & $-\overline{-}$ & $0.52(0.03)^{1}$ & $0.53(0.03)^{1}$ \\
Milk BHBA & $0.52(0.18)^{1}$ & - & $0.81(0.02)^{1}$ \\
Milk acetone & $0.52(0.21)^{1}$ & $0.90(0.06)^{1}$ & - \\
\hline
\end{tabular}

${ }^{1}$ The estimate differed significantly from zero $(P<0.001)$. 
not strongly associated with milk production potential in cows. This suggests that cows of similar productivity cope differently with metabolic stress induced by parturition and the initiation of lactation. This is supported by the research of Kessel et al. (2008), who observed that, despite similar milk yield and energy balance, some high-yielding cows did, whereas others did not, develop high plasma BHBA concentrations after calving.

Results thus show potential for genetic improvement of susceptibility to hyperketonemia but additional research on the physiological background of lower plasma BHBA concentrations in early-lactation cows should precede selection. Variation between cows exists in, for example, feed intake (Søndergaard et al., 2002; Vallimont et al., 2010), fat and protein mobilization (Tamminga et al., 1997; van der Drift et al., 2012a), and metabolic gene expression in the liver (Graber et al., 2010), which all influence the metabolic adaptation to NEB in early lactation.

The proportion of variance attributable to herd was larger than the additive genetic variance for all 3 investigated traits. This suggests that environmental factors have more influence in the etiology of hyperketonemia in a herd than genetic differences between cows. Feeding and management of cows in the dry weeks and early lactation period are considered as critical factors for prevention of hyperketonemia on dairy farms (Gerloff, 2000; Ingvartsen, 2006). Large differences in transition cow management exist between dairy farms, and herd prevalences of hyperketonemia ranged from 0 to $80 \%$ in our study (van der Drift et al., 2012b). Feeding regimens at dairy farms (i.e., the ration composition and concentrate feeding strategy) may also cause variation between herds in plasma ketone body concentrations due to differences in the cows' ruminal production of butyrate, which is absorbed by the rumen wall, and released as BHBA or acetoacetate (Huhtanen et al., 1993; Bruss, 2008). Despite the large proportion of variance attributable to herd effects, heritability estimates for ketone body concentrations were significant. Prevention strategies for hyperketonemia may, therefore, include both feeding and management strategies at dairy farms (short-term) and genetic improvement through breeding programs (long-term). As unfavorable genetic correlations between plasma BHBA concentrations and reproductive traits were observed (Oikonomou et al., 2008a), breeding for lower ketosis susceptibility may also contribute to genetic improvement of dairy cow fertility.

Phenotypic and genetic correlations between plasma concentrations of BHBA and milk concentrations were moderate. First, this could be explained by the difference in timing of sampling between blood and milk, as milk samples were pooled from the evening and morning milking, whereas blood was sampled between 1100 and $1400 \mathrm{~h}$ after test-day milk sampling in the morning. Also, ketone body metabolism in the mammary gland may differ between cows. The mammary gland extracts BHBA from the blood (Laarveld et al., 1985), which can be used for de novo synthesis of FA (Bauman and Griinari, 2003). Another explanation for the moderate correlations may be that FTIR spectroscopy analysis of acetone and BHBA concentrations in milk shows high, but not perfect, correlation with wet chemical analysis of these milk ketone bodies (approximately 0.80 for both traits; de Roos et al., 2007), indicating that some misclassification of milk samples can occur.

Analysis of the BHBA concentration in blood is considered the reference test for hyperketonemia in cows, but this analysis is not routinely performed in practice and is, thus, less suited for genetic evaluation of hyperketonemia susceptibility. $\beta$-Hydroxybutyrate and acetone concentrations are currently routinely analyzed by FTIR spectroscopy in test-day milk samples in the Netherlands and will, thus, become available for the vast majority of Dutch dairy cows in the near future. Both milk traits have similar genetic correlations with plasma BHBA concentration in early-lactation cows. As the genetic correlation between milk BHBA and milk acetone concentration was high (0.90), only one of these milk traits needs to incorporated in breeding programs when targeting for low plasma BHBA concentrations after calving. More genetic variation existed in milk BHBA concentrations, and response to selection will, therefore, be larger when this milk trait is used in the breeding program.

\section{CONCLUSIONS}

Differences were observed between cows and between herds in plasma and milk BHBA and milk acetone concentrations between 5 and 60 DIM. The heritability estimate of plasma BHBA concentration (0.17) indicates that selective breeding may contribute to lower susceptibility of cows to hyperketonemia in early lactation. The proportion of variance attributable to herd was large, supporting the importance of on-farm feeding and management in the etiology of hyperketonemia in fresh cows. Milk BHBA and milk acetone concentrations can be routinely analyzed at test days and may, therefore, provide a practical alternative for breeding programs, even if correlations with plasma BHBA concentrations are only moderate. Response to selection will be larger when milk BHBA concentrations are used in the breeding program, as this milk trait showed more genetic variation. 


\section{ACKNOWLEDGMENTS}

The authors thank the farmers for participating in the research and the Cattle Improvement Co-operative (CRV) organization (Arnhem, the Netherlands) for supplying pedigrees, milk production records, and breeding values.

\section{REFERENCES}

Bauman, D. E., and J. M. Griinari. 2003. Nutritional regulation of milk fat synthesis. Annu. Rev. Nutr. 23:203-227.

Bruss, M. L. 2008. Chapter 4: Lipids and ketones. Pages $81-115$ in Clinical Biochemistry of Domestic Animals. 6th ed. Academic Press, San Diego, CA.

Coffey, M. P., G. Simm, J. D. Oldham, W. G. Hill, and S. Brotherstone. 2004. Genotype and diet effects on energy balance in the first three lactations of dairy cows. J. Dairy Sci. 87:4318-4326.

de Roos, A. P. W., H. J. C. M. van den Bijgaart, J. Hørlyk, and G. de Jong. 2007. Screening for subclinical ketosis in dairy cattle by Fourier transform infrared spectrometry. J. Dairy Sci. 90:1761-1766.

Duffield, T. F., D. F. Kelton, K. E. Leslie, K. D. Lissemore, and J. H. Lumsden. 1997. Use of test day milk fat and milk protein to detect subclinical ketosis in dairy cattle in Ontario. Can. Vet. J. 38:713-718.

Duffield, T. F., K. D. Lissemore, B. W. McBride, and K. E. Leslie. 2009. Impact of hyperketonemia in early lactation dairy cows on health and production. J. Dairy Sci. 92:571-580.

Emanuelson, U., and L. Andersson. 1986. Genetic variation in milk acetone in Swedish dairy cows. Zentralbl. Veterinarmed. A 33:600608.

Gerloff, B. J. 2000. Dry cow management for the prevention of ketosis and fatty liver in dairy cows. Vet. Clin. North Am. Food Anim. Pract. 16:283-292.

Gilmour, A. R., B. J. Gogel, B. R. Cullis, and R. Thompson. 2009. ASReml User Guide. Release 3.0. VSN International Ltd., Hemel Hempstead, UK.

Graber, M., S. Kohler, T. Kaufmann, M. G. Doherr, R. M. Bruckmaier, and H. A. van Dorland. 2010. A field study on characteristics and diversity of gene expression in the liver of dairy cows during the transition period. J. Dairy Sci. 93:5200-5215.

Gröhn, Y., J. R. Thompson, and M. L. Bruss. 1984. Epidemiology and genetic basis of ketosis in Finnish Ayrshire cattle. Prev. Vet. Med. 3:65-77.

Heringstad, B., Y. M. Chang, D. Gianola, and G. Klemetsdal. 2005. Genetic analysis of clinical mastitis, milk fever, ketosis, and retained placenta in three lactations of Norwegian Red cows. J. Dairy Sci. 88:3273-3281.

Huhtanen, P., H. Miettinen, and M. Ylinen. 1993. Effect of increasing ruminal butyrate on milk yield and blood constituents in dairy cows fed a grass silage-based diet. J. Dairy Sci. 76:1114-1124.

Ingvartsen, K. L. 2006. Feeding- and management-related diseases in the transition cow: Physiological adaptations around calving and strategies to reduce feeding-related diseases. Anim. Feed Sci. Technol. 126:175-213.

Kessel, S., M. Stroehl, H. H. Meyer, S. Hiss, H. Sauerwein, F. J. Schwarz, and R. M. Bruckmaier. 2008. Individual variability in physiological adaptation to metabolic stress during early lactation in dairy cows kept under equal conditions. J. Anim. Sci. 86:2903-2912.

Laarveld, B., R. K. Chaplin, and R. P. Brockman. 1985. Effects of insulin on the metabolism of acetate, $\beta$-hydroxybutyrate and triglycerides by the bovine mammary gland. Comparative Biochem. Physiol. B 82:265-267.
LeBlanc, S. J., K. E. Leslie, and T. F. Duffield. 2005. Metabolic predictors of displaced abomasum in dairy cattle. J. Dairy Sci. $88: 159-170$.

Mäntysaari, E. A., Y. T. Grohn, and R. L. Quaas. 1991. Clinical ketosis: Phenotypic and genetic correlations between occurrences and with milk yield. J. Dairy Sci. 74:3985-3993.

Oetzel, G. R. 2004. Monitoring and testing dairy herds for metabolic disease. Vet. Clin. North Am. Food Anim. Pract. 20:651-674.

Oikonomou, G., G. Arsenos, G. E. Valergakis, A. Tsiaras, D. Zygoyiannis, and G. Banos. 2008a. Genetic relationship of body energy and blood metabolites with reproduction in Holstein cows. J. Dairy Sci. 91:4323-4332.

Oikonomou, G., G. E. Valergakis, G. Arsenos, N. Roubies, and G. Banos. 2008b. Genetic profile of body energy and blood metabolic traits across lactation in primiparous Holstein cows. J. Dairy Sci. 91:2814-2822.

Seifi, H. A., S. J. LeBlanc, K. E. Leslie, and T. F. Duffield. 2011. Metabolic predictors of post-partum disease and culling risk in dairy cattle. Vet. J. 188:216-220.

Søndergaard, E., M. K. Sørensen, I. L. Mao, and J. Jensen. 2002 Genetic parameters of production, feed intake, body weight, body composition, and udder health in lactating dairy cows. Livest. Prod. Sci. 77:23-34.

Tamminga, S., P. A. Luteijn, and R. G. M. Meijer. 1997. Changes in composition and energy content of liveweight loss in dairy cows with time after parturition. Livest. Prod. Sci. 52:31-38.

Tveit, B., F. Lingaas, M. Svendsen, and Ø. V. Sjaastad. 1992. Etiology of acetonemia in Norwegian cattle. 1. Effect of ketogenic silage, season, energy level, and genetic factors. J. Dairy Sci. 75:24212432.

Uribe, H. A., B. W. Kennedy, S. W. Martin, and D. F. Kelton. 1995 Genetic parameters for common health disorders of Holstein cows. J. Dairy Sci. 78:421-430.

Vallimont, J. E., C. D. Dechow, J. M. Daubert, M. W. Dekleva, J. W. Blum, C. M. Barlieb, W. Liu, G. A. Varga, A. J. Heinrichs, and C. R. Baumrucker. 2010. Genetic parameters of feed intake, production, body weight, body condition score, and selected type traits of Holstein cows in commercial tie-stall barns. J. Dairy Sci. 93:4892-4901.

van der Drift, S. G. A., M. Houweling, J. T. Schonewille, A. G. M. Tielens, and R. Jorritsma. 2012a. Protein and fat mobilization and associations with serum $\beta$-hydroxybutyrate concentrations in dairy cows. J. Dairy Sci. 95:4911-4920. http://dx.doi.org/10.3168/ jds.2011-4771

van der Drift, S. G. A., R. Jorritsma, J. T. Schonewille, H. M. Knijn, and J. A. Stegeman. 2012b. Routine detection of hyperketonemia in dairy cows using Fourier transform infrared spectroscopy analysis of $\beta$-hydroxybutyrate and acetone in milk in combination with test-day information. J. Dairy Sci. 95:4886-4898. http://dx.doi. org/10.3168/jds.2011-4417.

Van Dorp, T. E., J. C. M. Dekkers, S. W. Martin, and J. P. T. M. Noordhuizen. 1998. Genetic parameters of health disorders, and relationships with 305-day milk yield and conformation traits of registered Holstein cows. J. Dairy Sci. 81:2264-2270.

Veerkamp, R. F., B. Beerda, and T. van der Lende. 2003. Effects of genetic selection for milk yield on energy balance, levels of hormones, and metabolites in lactating cattle, and possible links to reduced fertility. Livest. Prod. Sci. 83:257-275.

Walsh, R. B., J. S. Walton, D. F. Kelton, S. J. LeBlanc, K. E. Leslie, and T. F. Duffield. 2007. The effect of subclinical ketosis in early lactation on reproductive performance of postpartum dairy cows. J. Dairy Sci. 90:2788-2796.

Wood, G. M., P. J. Boettcher, D. F. Kelton, and G. B. Jansen. 2004. Phenotypic and genetic influences on test-day measures of acetone concentration in milk. J. Dairy Sci. 87:1108-1114. 